\title{
FASE CRÔNICA CARDÍACA FIBROSANTE DA TRIPANOSSOMÍASE CRUZI EXPERIMENTAL NO CÃO
}

\author{
Marta de Lana', Washington L. Tafurl2, Marcelo V. Caliari', Eduardo A. Bambirra 4 , \\ Cléa de A. Chiari3 ${ }^{3}$, Virgínea H. Rios Leite ${ }^{4}$, Alfredo J. A. Barbosa ${ }^{4}$, Max Jean O. Toledo', \\ - Egler Chiari3
}

\begin{abstract}
Os autores documentam a cardiopatia difusa fibrosante, com todos os sintomas clínicos e dados de autópsia pertinentes à insuficiência cardíaca congestiva, em um dos 21 cães infectados com a cepa Colombiana (cinco morreram na fase aguda e quatro continuam vivos) e cinco, dos 13 infectados com a cepa Berenice-78 (oito morreram na fase aguda), num periodo de oito anos de observação.

Em vista destes resultados, os autores sugerem que o cão possa vir a ser um modelo experimental, adequado para o estudo da história natural da doença de Chagas, preenchendo os requisitos estabelecidos pelo Comitê Assessor de Doença de Chagas do Programa Especial de Pesquisa e Treinamento em Doenças Tropicais da Organização Mundial de Saúde.
\end{abstract}

Palavras-chaves: Trypanosoma cruzi. Cardiopatia chagásica. Cão. Modelo experimental. Fibrose.

De acordo com os trabalhos publicados até o momento, o cão está sendo considerado, com ressalvas, como modelo ideal para o estudo da fase aguda e crônica indeterminada da tripanossomíase cruzi1 23456714151819202124 .

Os requisitos para um modelo ideal, estabelecidos pelo Comitê de Doença de Chagas do Programa Especial de Treinamento e Pesquisa de Doenças Parasitárias da Organização Mundial de Saúde25 podem ser assim discriminados: permitir o isolamento do parasito ao longo do curso da infecção; apresentar reações sorológicas positivas, indicativas da persistência da infecção; apresentar manifestações clínicas da doença de Chagas crônica; desenvolver miocardite, miosite e outras alterações patológicas que caracterizam a doença; induzir a resposta imune contra tecido do hospedeiro.

Há mais de oito anos estamos a procura de um modelo que não somente preencha todos os requisitos acima citados mas, principalmente, que desenvolva a cardiopatia grave evolutiva fibrosante com todas al-

Trabalho financiado pela FINEP - Proc. no 43.86.0762.00, CNPq-PIDE.

1. Departamento de Análises Clínicas, Escola de Farmácia, Universidade Federal de Ouro Preto, Ouro Preto, MG.

2. Departamento de Ciểncias Biológicas, Instituto de Ciências Exatas e Biológicas, Universidade Federal de Ouro Preto, Ouro Preto, MG.

3. Departamento de Parasitologia, Instituto de Ciências Biológicas, Belo Horizonte, MG.

4. Departamento de Anatomia Patológica, Faculdade de Medicina, Universidade Federal de Minas Gerais, Belo Horizonte, MG.

Recebido para publicação em 23/5/88. terações clínicas observadas na forma humana. Até o momento, os resultados que encontramos parecem indicar que alcançamos tal objetivo no modelo cão. A partir destes resultados e dos de outros autores, tentaremos aplicar metodologia moderna no estudo dos vários fatores patogenéticos no pressuposto de que, assim, será possivel chegar ao esclarecimento da patogenia e de fisiopatologia das diferentes formas anatomoclínicas da doença. Dentre os numerosos fatores patogenéticos até agora aventados, a fibrose nos parece o mais importante na determinação da insuficiência cardiaca congestiva (ICC) e da aperistalse. Năo existe qualquer outra cardiopatia e/ou mega com aspecto tão peculiar. No miocárdio bem como nos megas, a fibrose (fibrilopoese) é focal e difusa ao mesmo tempo ${ }^{23}$.

O presente trabalho tem a finalidade de documentar a fase crônica da doença de Chagas em cães que recebem inóculos diversos das cepas Colombiana ${ }^{13}$ e Berenice- $78^{17}$ de $T$. cruzi, destacando aqueles animais que desenvolveram a cardiopatia fibrosante, com sinais e sintomas clinicos de ICC.

\section{MATERIAL E MÉTODOS}

Animais infectados com a cepa Colombiana ${ }^{13}$ de T. cruzi.

Antes da inoculação da cepa Colombiana, em cães, foi traçada sua curva de parasitemia em camundongos albinos nos quais vinha sendo mantida em laboratório através de passagens sangüineas sucessivas ao longo do tempo. Tal experimento teve a finalidade de verificar o comportamento dessa cepa em camundongos antes de sua inoculação no cão.

Foram utilizados 36 cães Pinscher, jovens, com 50 dias de idade, de raça pura, com registro e controle 
no Kennel Club do Brasil. Desses animais (16 machos e 15 fêmeas), 21 foram inoculados com 1000 tripomastigotas sangüineos/g de peso, intraperitonealmente e os demais serviram de grupo-controle.

Após a inoculação, os cães foram avaliados clínica e parasitologicamente 7 .

Todos os animais inoculados infectaram-se; cinco desenvolveram a fase aguda com óbito e dezesseis desenvolveram a fase subaguda e crônica com 11 obitos $^{7}$. Cinco animais infectados restantes e dois controles sobreviveram por mais de sete anos à infecção sendo, a partir de 1985, submetidos a quatro avaliações sucessivas através de xenodiagnóstico, hemocultura e reaçāo de imunofluorescência indireta (RIFI). Os que apresentaram exames parasitológicos negativos foram, numa segunda fase (1987), avaliados semanalmente através de xenodiagnóstico. Em cada xenodiagnóstico foram utilizadas 10 ninfas de 2? estádio da espécie Dipetalogaster maximus.

Nessa oportunidade foram isolados parasitos dos cảes cronicamente infectados e inoculados em um grupo de camundongos albinos. Já numa segunda passagem, nesses animais, foi feita uma curva de parasitemia paralela à cepa Colombiana que vinha sendo mantida em laboratório através de passagens sangüíneas sucessivas ao longo dos anos. Este ex- perimento, juntamente com os seguintes, teve a finalidade de permitir a comparação em camundongos albinos, do comportamento apresentado por três subpopulações de parasitos da cepa Colombiana em três situações distintas: ( $a$ ) Antes de sua inoculação nos cães Pinscher; (b) Após mais de oito anos de permanência no organismo desses cães; (c) Após manutenção em laboratório, por esse mesmo intervalo de tempo, através de passagens sangüíneas sucessivas em camundongos albinos.

Todos os cães cronicamente infectados com a cepa Colombiana ${ }^{13}$ encontravam-se na forma indeterminada sendo observados diariamente e mantidos em canil adequado com àgua e ração balanceada. Um destes animais morreu sob ação de anestesia sendo autopsiado por completo para observaçōes anátomohistopatológicas.

\section{Animais infectados com a cepa Berenice-78 $(B e-78)^{17}$ de T. cruzi:}

Mais recentemente, trabalhando com a cepa BE-78, foram inoculados com tripomastigotas sangüineos um total de 13 cães jovens (idade entre cinco dias e quatro meses), de raça não definida, segundo o quadro abaixo:

\section{Esquema de inoculação de cães}

\begin{tabular}{rcrcc}
\hline Grupo no & $\begin{array}{c}\text { No animais } \\
\text { por grupo }\end{array}$ & Idade & $\begin{array}{c}\text { Inóculo } \\
\text { peso corporal }\end{array}$ & $\begin{array}{c}\text { Via } \\
\text { inoculação }\end{array}$ \\
\hline I & 4 & 4 meses & 1000 trip./g peso & IP; SC; EV; CO \\
II & 2 & 5 dias & IP \\
III & 2 & 18 dias & 200 trip. $/ \mathrm{kg}$ peso & CO \\
IV & 2 & 3 meses & 2000 trip. $/ \mathrm{kg}$ peso & IP \\
V & 3 & 50 dias & &
\end{tabular}

Durante a fase aguda da infecção esses animais foram observados diariamente sendo avaliados: curva de parasitemia ${ }^{9}$, temperatura retal, comportamento e aspecto clínicos. Nessa fase da infecção foram realizadas autópsias em alguns animais que apresentavam o quadro clínico compativel com a fase aguda da doença.

Os cães que sobreviveram a fase aguda da infecção foram mantidos em canil adequado, sendo autopsiados em diferentes momentos da fase crônica, em função da evolução do quadro clínico ou quando faleciam naturalmente.

Tanto os cães em fase aguda quanto os de fase crônica, falecidos naturalmente e/ou sacrificados de acordo com cronograma por nós delineado, foram autopsiados de modo completo, sendo coletados fragmentos de todos os órgãos. O coraçāo foi guardado in totum. Foi empregado como fixador o formol a $10 \%$ em tampão fosfato $\mathrm{pH} 7,2$. Os átrios foram incluídos em parafina in totum para posterior estudo do sistema nervoso autônomo e da evolução do processo inflamatório. Também foram incluidos e processados fragmentos dos ventriculos. Os cortes foram corados pela hematoxilina-eosina ou pelo tricrômico de Gomori; alguns sendo processados para a pesquisa de amastigotas pela técnica de peroxidase-antiperoxidase (PAP) ${ }^{8}$.

A cepa Be-78 vinha sendo mantida em laboratório através de passagens sangüineas sucessivas em camundongos. Antes de sua inoculação em cães, foi traçada curva de parasitemia nesses animais com a finalidade de verificar seu comportamento naquele momento. 
Lana M, Tafuri WL, Caliari MV, Bambirra EA, Chiari CA, Leite VHR, Barbosa AJA, Toledo MJO, Chiari E. Fase crônica fibrosante da tripanossomíase cruzi experimental no cão. Revista da Sociedade Brasileira de Medicina Tropical 21:113-121, Jul-Set, 1988

\section{RESULTADOS}

\section{Animais infectados com a cepa Colombiana ${ }^{13}$ de} T. cruzi:

A avaliação sorológica dos cinco cães que sobreviveram à fase aguda com mais de sete anos de infecção revelou anticorpos anti-T. cruzi em todos os animais, com titulos que variaram entre 320 e 2560 (conjugado anti-imunoglobulina total). Em quatro avaliações sucessivas, realizadas em 1985 e 1986, um cão apresentou hemocultura e xenodiagnóstico positivos, um apresentou apenas o xenodiagnóstico positivo e outro morreu acidentalmente por choque anestésico, sendo autopsiado por completo revelando miocardite crônica discreta focal sem nenhuma alteração macroscópica do sistema digestivo. Na segunda fase da avaliação, feita em 1987, foi realizado xenodiagnóstico sendo detectados parasitas em mais um dos animais, restando apenas um cão com RIFI anti- $T$. cruzi reativa e exame parasitológico negativo (Tabela 1). Nesse animal estão sendo feitos xenodiagnósticos repetidos com o objetivo de detectar parasitos sangüineos.

A análise das curvas de parasitemia em camundondos albinos relativos aos parasitos da cepa Colombiana ${ }^{13}$ obtidos em três situações distintas revelou: (a) Camundongos inoculados com parasitos dessa cepa, antes da inoculação dos cães Pinscher apresentaram curva de parasitemia, do tipo ascendente, com período pré-patente de cinco dias e morte de todos os animais até o 22\% dia da infecção (Figura 1); (b) Camundongos inoculados com parasitos isolados de câes com infeç̧ão crônica, após mais de oito anos de infecção, apresentaram curva de parasitemia de perfil irregular, com periodo pré-patente de seis dias, com maior elevação da parasitemia entre o $22 \%$ e 35 \% dia; periodo patente entre o sexto e 80 \% dia,

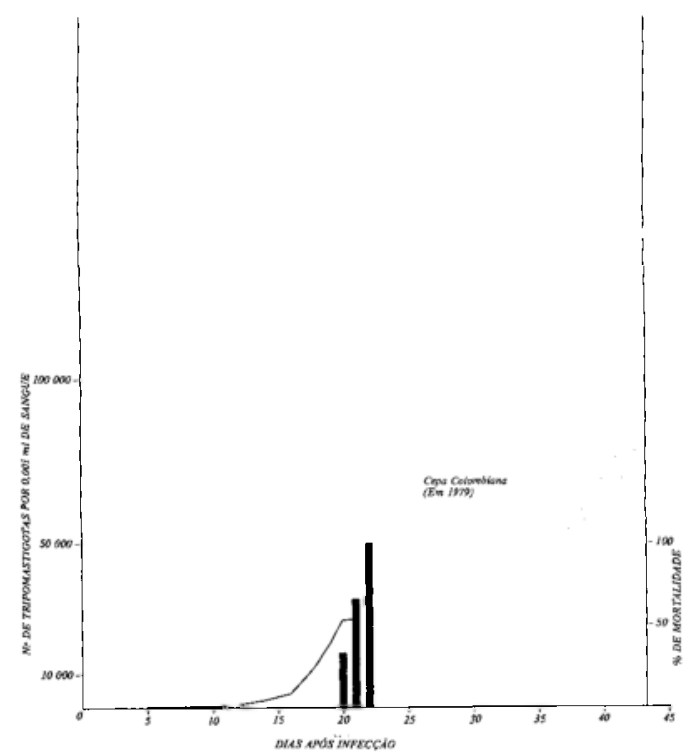

Fig. 1 - Curva de parasitemia e percentagem cumulativa de mortalidade de camundongos albinos inoculados com tripomastigotas sangüíneos da cepa Colombiana, antes da sua inoculação em cães Pinscher.

Inóculo: 100.000 tripomastigotas sangüíneos Via: intraperitoneal

com total sobrevivência dos animais à fase aguda da infecção por pelo menos 120 dias após inoculação (Figura 2); (c) Camundongos inoculados com parasitos da cepa Colombiana que vinham sendo mantidos em laboratório ao longo deste mesmo intervalo de tempo, através de passagens sangüineas sucessivas, apre-

Tabela 1 - Avaliação parasitológica, sorológica e histológica em cães com infecção crônica, pela cepa Colombiana de $\mathrm{T}$. cruzi, inoculados em novembro de 1979

\begin{tabular}{|c|c|c|c|c|c|c|c|c|c|c|c|c|c|c|c|c|c|c|c|c|c|}
\hline \multirow{3}{*}{$\mathrm{Ne}$} & \multirow{3}{*}{$\begin{array}{r}1985 \\
\text { RIFII } \\
\end{array}$} & \multicolumn{19}{|c|}{ Data e Tipo de Exame } & \multirow{3}{*}{ Exame } \\
\hline & & & & \multicolumn{7}{|c|}{1986} & \multicolumn{5}{|c|}{1987} & \multirow[b]{2}{*}{$\begin{array}{c}24 / \operatorname{sun} \\
\mathrm{X}\end{array}$} & \multirow[b]{2}{*}{$\begin{array}{c}01 / \mathrm{Jul} \\
\mathrm{X}\end{array}$} & \multirow[b]{2}{*}{$\begin{array}{c}15 / \text { Jul } \\
\mathrm{X}\end{array}$} & \multirow[b]{2}{*}{$\begin{array}{c}12 / A_{g 0} \\
X\end{array}$} & \multirow[b]{2}{*}{$\begin{array}{c}26 / \mathrm{Ago} \\
\mathrm{X}\end{array}$} & \\
\hline & & \multicolumn{2}{|c|}{$\begin{array}{c}24 / \text { Out } \\
\mathrm{X}^{2} \mathrm{H}^{3}\end{array}$} & $\mathrm{x}$ & H & $\begin{array}{l}04 / \mathrm{Fev} \\
\text { HIST } 6\end{array}$ & \multicolumn{2}{|c|}{ 09/Jul } & \multicolumn{2}{|c|}{$\begin{array}{l}10 / \text { unt } \\
\mathrm{X}^{\mathrm{H}} \mathrm{H}\end{array}$} & $\begin{array}{c}\text { 13/Maio } \\
\mathrm{X}\end{array}$ & $\begin{array}{c}\text { 20/Maio } \\
\mathrm{X}\end{array}$ & $\begin{array}{c}\text { 27/Maio } \\
\mathrm{X}\end{array}$ & $\begin{array}{c}\text { 03/Jun } \\
\mathrm{X}\end{array}$ & $\begin{array}{c}10 / \text { Iun } \\
\mathrm{X}\end{array}$ & & & & & & \\
\hline 1 & $1 / 2560$ & - & - & - & - & + & .. & .. & .. & .. & .. & $\ldots$ & .. & .. & .. & .. & .. & .. & $\cdots$ & .. & + \\
\hline 2 & $1 / 2560$ & + & - & .. & .. & .. & .. & .. & .. & .. & .. & .. & .. & .. & .. & .. & .. & .. & .. & $\because$ & + \\
\hline 3 & $1 / 320$ & - & - & - & - & .. & - & $\because$ & - & $\because$ & - & - & - & - & - & - & - & $\ddot{-}$ & $\ddot{-}$ & $\ddot{-}$ & - \\
\hline 4 & $1 / 320$ & - & - & - & - & .. & - & - & - & - & - & - & - & - & - & - & + & - & - & - & + \\
\hline 5 & $1 / 640$ & + & + & .. & .. & .. & .. & .. & .. &. & - & + & - & + & - & - & - & - & - & + & + \\
\hline 6 & Controle & - & $\bar{z}+$ & .. & . & .. & $\cdot \cdot$ & .. & .. & .. & .. & .. & .. & .. & .. & .. & .. & .. & .. & .. & - \\
\hline 7 & Controle & - & - & .. & .. & .. & . & .. &.. & -. & $\cdots$ & . & .. & .. & .. & .. & 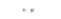 & .. &.. & .. & - \\
\hline
\end{tabular}

${ }^{1}$ Reação de Imunofluorescência Indireta; ${ }^{2}$ Xenodiagnóstico; ${ }^{3}$ Hemocultura; ${ }^{4}$ Histopatologia; .. Exame não realizado;

- Exame negativo; + Exame positivo. 

fibrosante da tripanossomías cruzi experimental no cão. Revista da Sociedade Brasileira de Medicina Tropical 21: 113-121, Jul-Set, 1988

sentaram curva de parasitemia muito elevada do tipo ascendente, com período pré-patente de cinco dias e morte de todos até o 25 o dia de infecção (Figura 3).

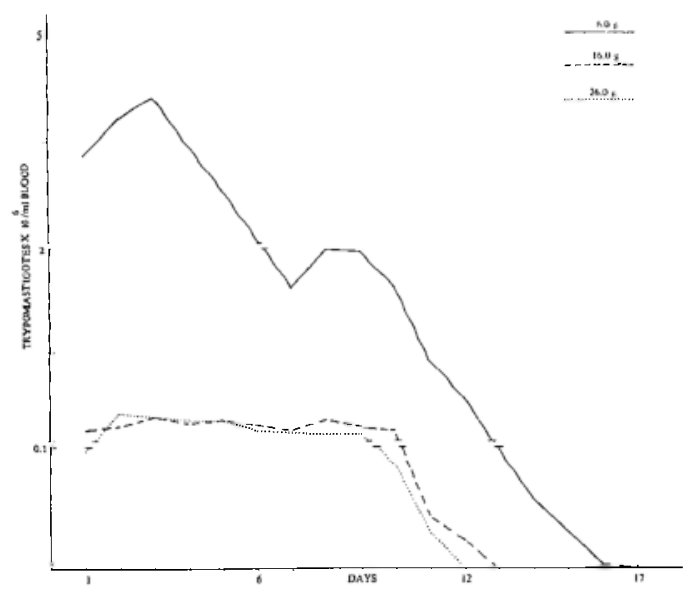

Fig. 2 - Curva de parasitemia em camundongos albinos inoculados com tripomastigotas sangüineos da cepa Colombiana isolada de cāes Pinscher crônicos após oito anos de infecçào.

Inóculo: 100.000 tripomastigotas sangüíneos Via: intraperitoneal

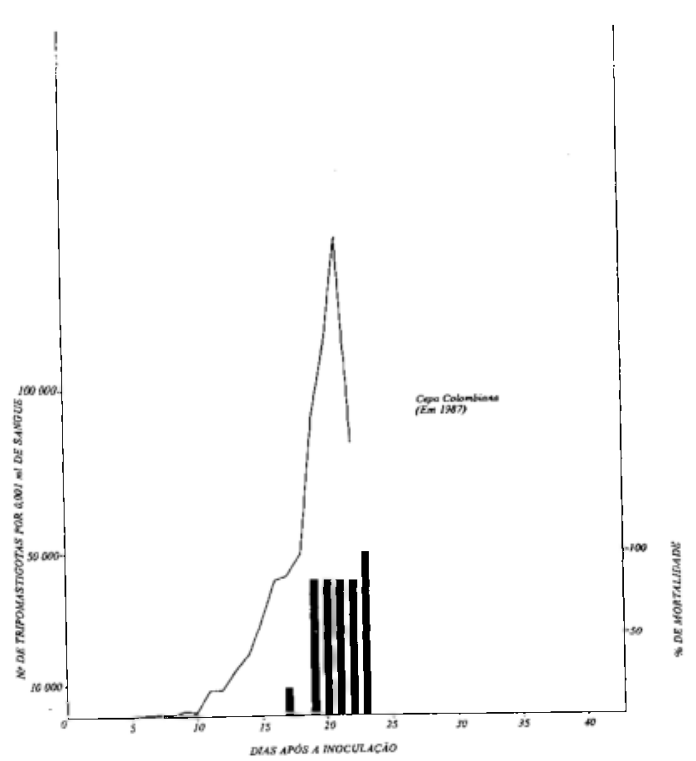

Fig. 3 - Curva de parasitemia e percentagem cumulativa de mortalidade de camundongos albinos inoculados com tripomastigotas sangüineos da cepa Colombiana de $\mathbf{T}$. cruzi nos quais vem sendo mantida em laboratório ao longo dos anos, através de passagens sangüineas sucessivas. Inóculo: 100.000 tripomastigotas sangüineos Via intraperitoneal
Animais infectados com a cepa Be-7817 de T. cruzi:

Todos os cães inoculados com a cepa Be-78, nas diferantes situações descritas, apresentaram parasitemia patente.

As alterações clínicas e comportamentais mais bbservadas foram: elevação da temperatura até $39,7^{\circ} \mathrm{C}$ em alguns animais, ascite, anorexia, entristecimento, perda de peso, caquexia (às vezes com paralisia dos membros posteriores), dificuldade respiratória (acompanhada de queda de temperatura que atingiu até $35^{\circ} \mathrm{C}$ ) seguida de morte dos animais. Oito cães foram autopsiados na fase aguda. Dos 13 cães infectados, com a cepa Be-78 ${ }^{17}$, cinco sobreviveram à fase aguda da infecção e evoluíram para a fase crônica indeterminada. Dois deles (grupo I) tiveram morte súbita sobrevivendo após a inoculação 331 e 854 dias, respectivamente. Outro cão foi autopsiado com 864 dias (grupo I) de infecção, pois apresentou após a morte súbita de seu irmão e companheiro de cela um quadro progressivo de tristeza, anorexia, perda de peso, dificuldade respiratória, queda de temperatura e paralisia geral.

Dois cães foram autopsiados respectivamente no $100 \%$ (grupo II) e no $526 \%$ dia de infecção (grupo IV), com sinais de insuficiência cardíaca congestiva (ICC). Até o momento nào foram detectadas alterações macroscópicas do sistema digestivo destes animais.

A análise das curvas de parasitemia, da cepa Be-78, em camundongos albinos, antes de sua inoculação em cães, revelou curvas de parasitemia de perfil irregular, período pré-patente de seis dias, periodo patente de 34 dias com total sobrevivência dos animais à fase aguda da infecção.

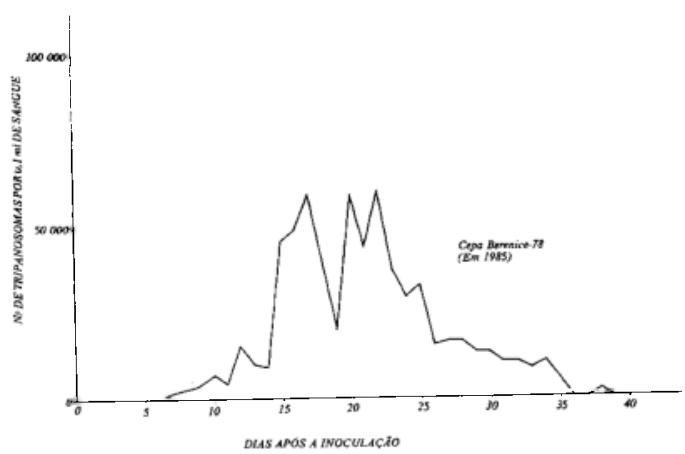

Fig. 4 - Curva de parasitemia em camundongos albinos inoculados com tripomastigotas sangüneos da cepa Be-78 de T. cruzi, antes de sua inoculaçōo em câes.

Inóculo: 50.000 tripomastigotas sangütneos Via: intraperitoneal 
Lana M, Tafuri WL, Caliari MV, Bambirra EA, Chiari CA, Leite VHR, Barbosa AJA, Toledo MJO, Chiari E. Fase crônica fibrosante da tripanossomiase cruzi experimental no cão. Revista da Sociedade Brasileira de Medicina Tropical 21:113-121, Jul-Set, 1988

Como a finalidade deste trabalho é a de documentar a cardiopatia chagásica crônica fibrosante em cães infectados experimentalmente com diferentes cepas e inóculos de T. cruzi, descreveremos a seguir, em conjunto, o que foi observado até o momento, no coração dos animais com a doença crônica.

Todos os corações mostraram-se aumentados de volume e de peso, em relação aos animais-controle, apresentando-se congestos, globosos, ponta sem lesão vorticilar e cone da pulmonar abaulado. Em um deles (Figura 5A, B, C) o epicárdio mostrou espessamentos moniliformes ao longo do ramo ascendente da coronária esquerda, placas fibrosas na fase posterior, bem como espessamentos cordonais, muito semelhantes ao observado na cardiopatia chagásica humana. À microscopia ótica, as lesões epicárdicas mostraram aspectos evolutivos diversos, desde lesões inflamatórias predominantemente exsudativas até a formação da placa fibrosa (Figuras 6A, B e C).
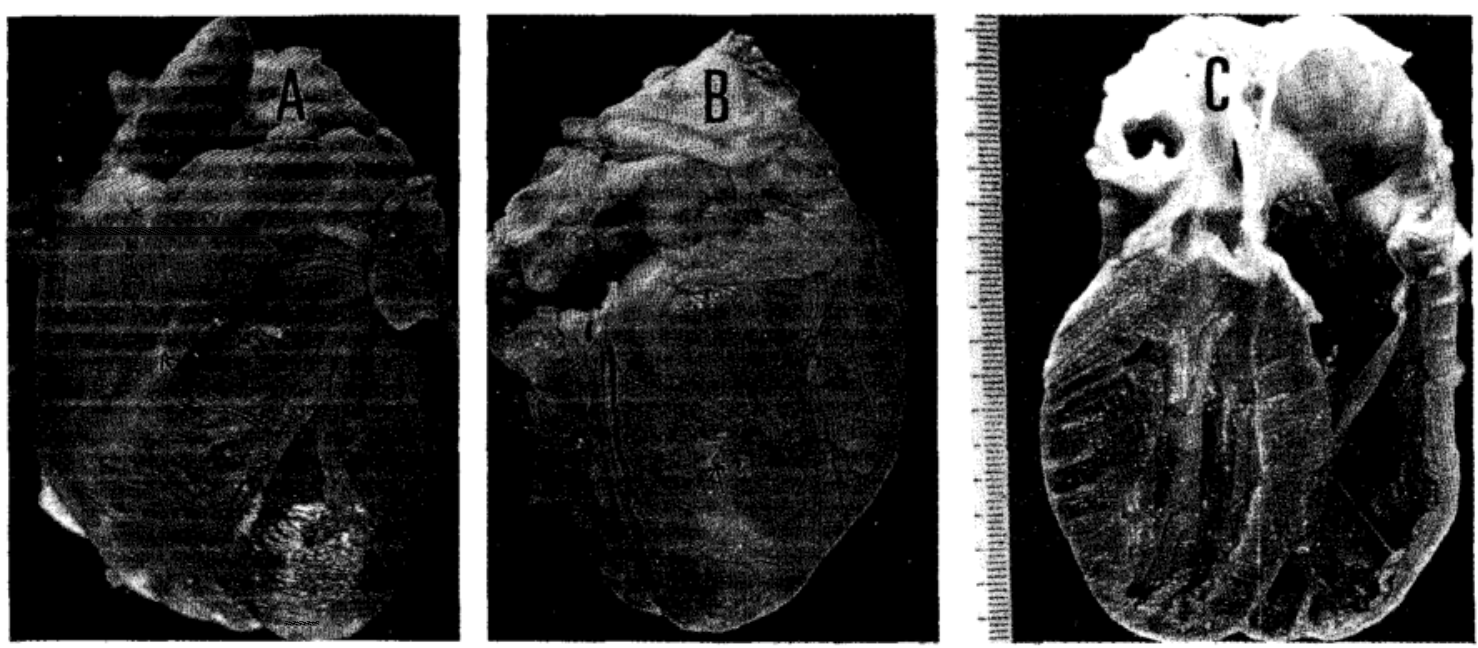

Fig. 5A,B,C - Cão de raça nãodefinida inoculado com oT. cruzi da cepa Berenice-78 e falecido após 13 meses de infecção. Coração aumentado de volume, congesto, câmaras dilatadas com espessamentos moniliformes e em placa no epicárdio (setas). Dilatação das cavidades cardiacas especialmente as da direita.
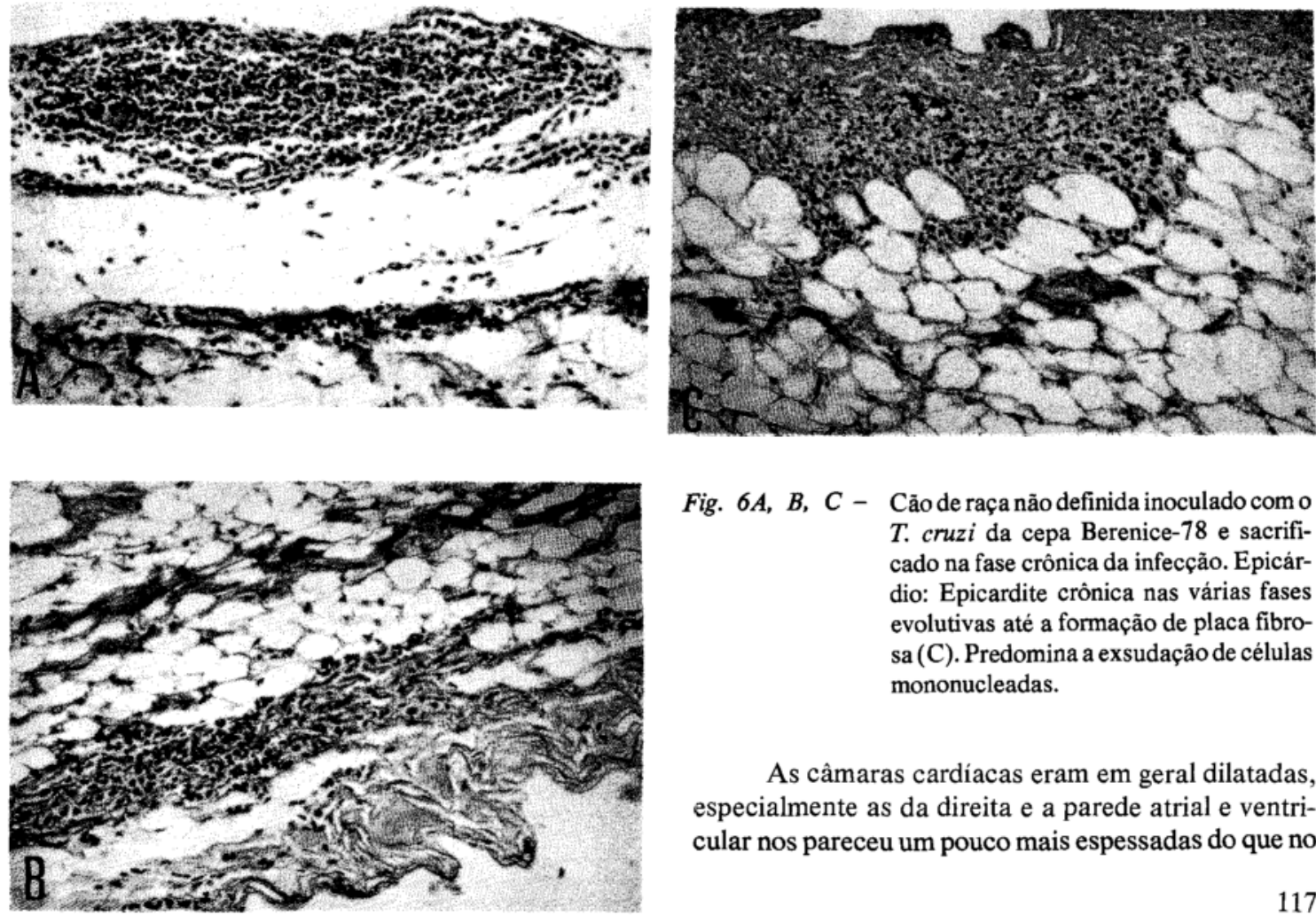

Fig. 6A, B, C - Cão de raça não definida inoculado como T. cruzi da cepa Berenice- 78 e sacrificado na fase crônica da infecção. Epicárdio: Epicardite crônica nas várias fases evolutivas até a formação de placa fibrosa (C). Predomina a exsudação de células mononucleadas.

As câmaras cardíacas eram em geral dilatadas, especialmente as da direita e a parede atrial e ventricular nos pareceu um pouco mais espessadas do que no 
Lana M, Tafuri WL, Caliari MV, Bambirra EA, Chiari CA, Leite VHR, Barbosa AJA, Toledo MJO, Chiari E. Fase crônica fibrosante da tripanossomíase cruzi experimental no cão. Revista da Sociedade Brasileira de Medicina Tropical 21: 113-121, Jul-Set, 1988

animal-controle. Não havia trombos. Os átrios foram examinados, in totum, em cortes semi-seriados e as lesões vistas até o momento foram: miocardite, periganglionite, perineurite, neurite, paraganglionite focais ou difusas, com exsudato predominantemente de células mononucleares e lesões regressivas pronunciadas dos neurônios (tigrólise central e periférica, picnose, cariólise, encarquilhamento e, por vezes, desaparecimento dos neurônios com proliferação nodular das células satélites (figuras $7 \mathrm{~A}, \mathrm{~B}$ e $\mathrm{C}$ e
$8 \mathrm{~A}$ e B). $\mathrm{O}$ tecido gorduroso subepicárdico, por vezes, mostrou-se inflamado, com exsudação difusa ou focal granulomatosa (figuras 10A, B e C) relacionada direta ou indiretamente com as estruturas nervosas.

Nos vários cortes examinados para análise do miocárdio eram constantes: miocardite crônica produtiva, ora local, ora difusa devido à confluência dos focos; exsudação das células predominantemente mononucleadas intimamente relacionadas com as células cardiacas (escalonadas ao longo das demais).
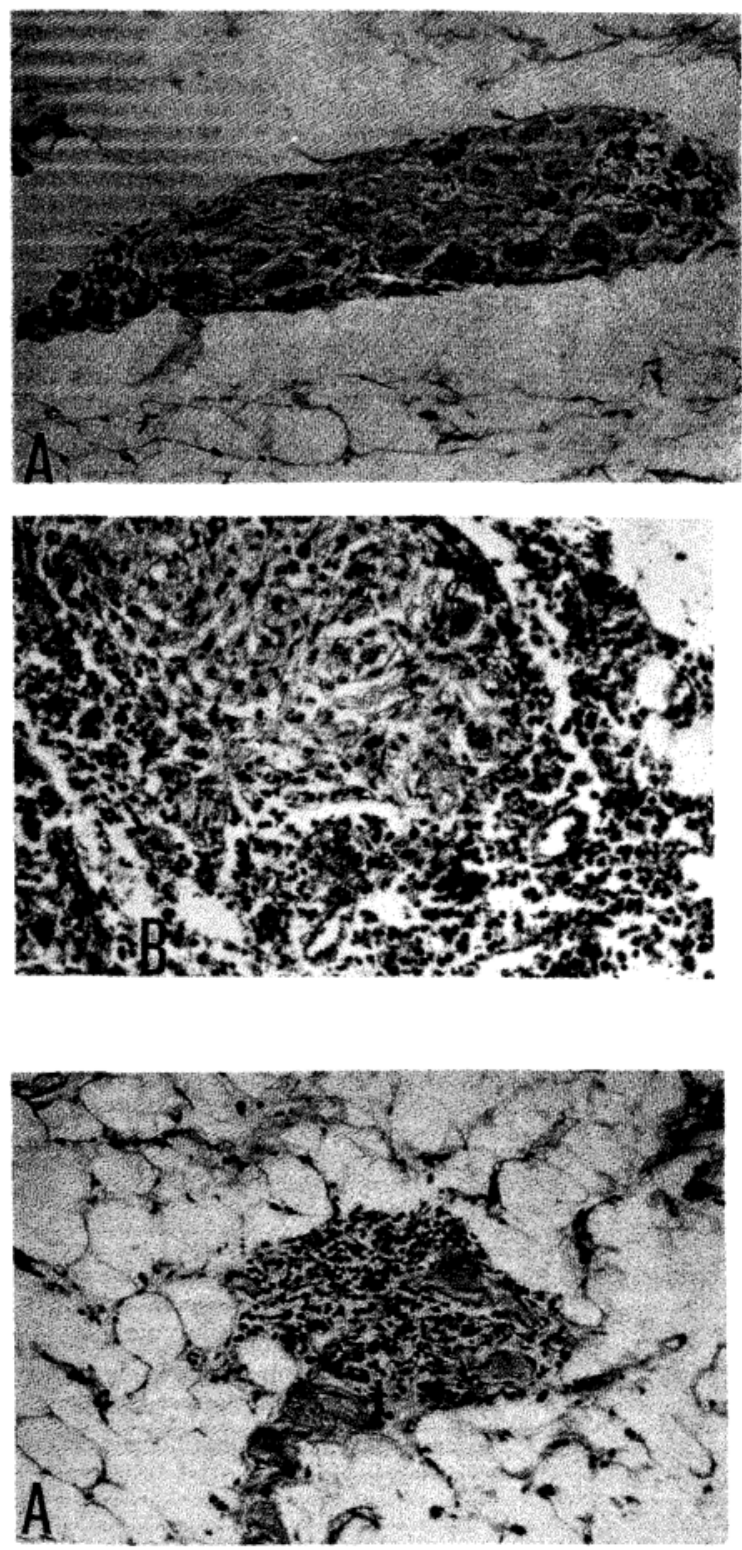

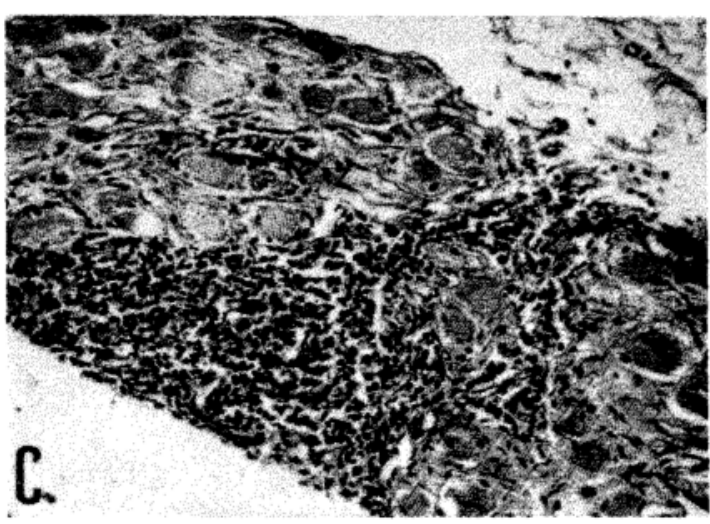

Fig. 7A, B, C - Cão de raça definida inoculado com a cepa Berenice-78 e autopsiado na fase crônica da infecção. (A) Periganglionite e ganglionite crònicas fecais; tecido gorduroso periganglionar integro; (B) Periganglionite e ganglionite crônicas com intensos fenômenos regressivos dos neurônios e inicio de formação de nódulos de Nageote; (C) Ganglionite focal com intensa exsudação de células mononucleadas e acentuadas fenomenos regressivos dos neurônios.

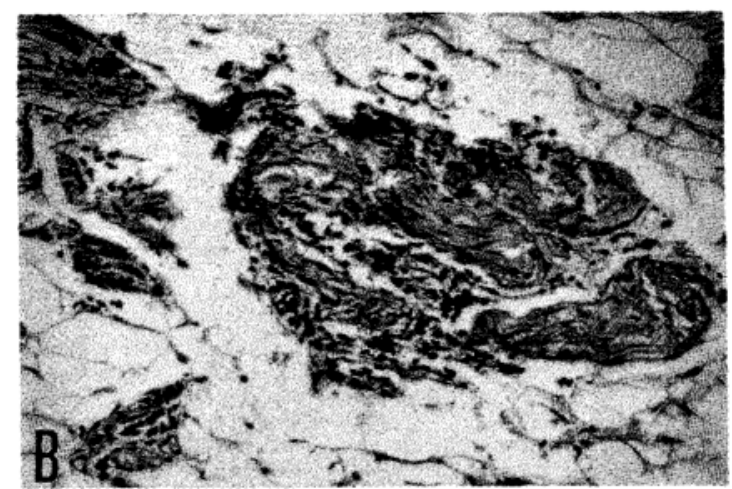

Fig. 8A, B, - Cāo de raça não definida inoculado com a cepa Berenice-78 e autopsiado na fase crônica. Feixes de fibras nervosas do plexo cardíaco superficial. Perineurite e neurite crônicas com exsudação predominantemente linfocitária. 
Lana M, Tafuri WL, Caliari MV, Bambirra EA, Chiari CA, Leite VHR, Barbosa AJA, Toledo MJO, Chiari E. Fase crônica fibrosante da tripanossomiase cruzi experimental no cão. Revista da Sociedade Brasileira de Medicina Tropical 21: 113-121, Jul-Set, 1988

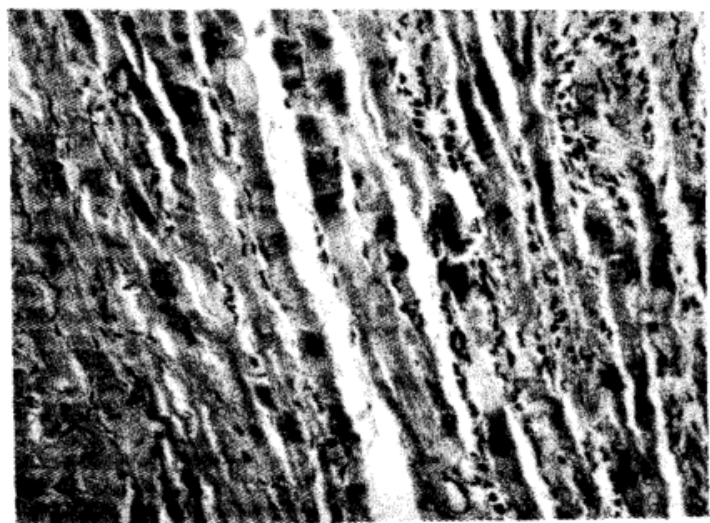

Fig. 9 - Cão de raça não definida inoculado com $T$. cruzi da cepa Berenice-78 e autopsiado na fase crónica de doença. Miocardite crônica com lesões regressivas das células cardiacas (lesão de Magarinos Torres).

$\mathrm{Na}$ maioria das vezes, nesses focos, as células cardiacas apresentavam-se mais ou menos intensamente lesadas com homogeneização do sarcoplasma devido à perda da estriação transversal e longitudinal com conseqüente acidofilia em tudo semelhante à lesão descrita por Magarinos Torres (Figuras 10C e $11 \mathrm{~A} \mathrm{e} \mathrm{B).}$

$O$ achado de granulomas foi raro, mas em um dos cães, estiveram presentes granulomas nas diferentes fases evolutivas, desde o predominantemente exsudativo (Figura 10A) até o exsudativo produtivo (Figuras 10B e C), com células gigantes tipo Langhans. A pesquisa de amastigotas foi positiva, porém os ninhos eram raros e com formas de parasita degeneradas às vezes só detectados pela técnica de $\mathrm{PAP}^{8}$.

Em todos os corações ocorreu fibrose ora do tipo cicatricial, relacionada com o processo de cura do foco inflamatório e uma outra mais difusa, não relacionada com a inflação e que afastava grupos de células cardiacas ou então insinuava-se entre elas, dando a nitida impressão de desorganização dos feixes de fibras masculares. $\mathrm{O}$ colágeno neoformado parece ser de várias idades, ora muito jovem, constituido de fibras muito delgadas, ora mais velho, denso e acidófilo.

\section{DISCUSSÃO}

Baseados em nossos resultados, somos de opinião que tanto o cão Pinscher inoculado com o T. cruzi, da cepa Colombiana ${ }^{13}$, quanto o cão jovem, de raça não definida, inoculado com o $T$. cruzi, da cepa Berenice- $78^{17}$, podem passar para a forma indeterminada podendo, de um momento para o outro, apresentarem sinais e sintomas de falência cardiaca e virem a falecer subitamente ou não. A autópsia revelou cardiopatia fibrosante clássica, mas até o momento não foram detectadas quaisquer alteraçōes do sistema digestivo (megas). De acordo com Andrade \& Andrade ${ }^{2}$, o cão apresenta aspectos evolutivos clínicos e anatomo-patológicos imprevisíveis ao longo da infecção e neste caso, estamos de acordo com esses autores. Isto, de fato, encarece e dificulta os estudos, mas por outro lado, mostra a semelhança da evolução da doença
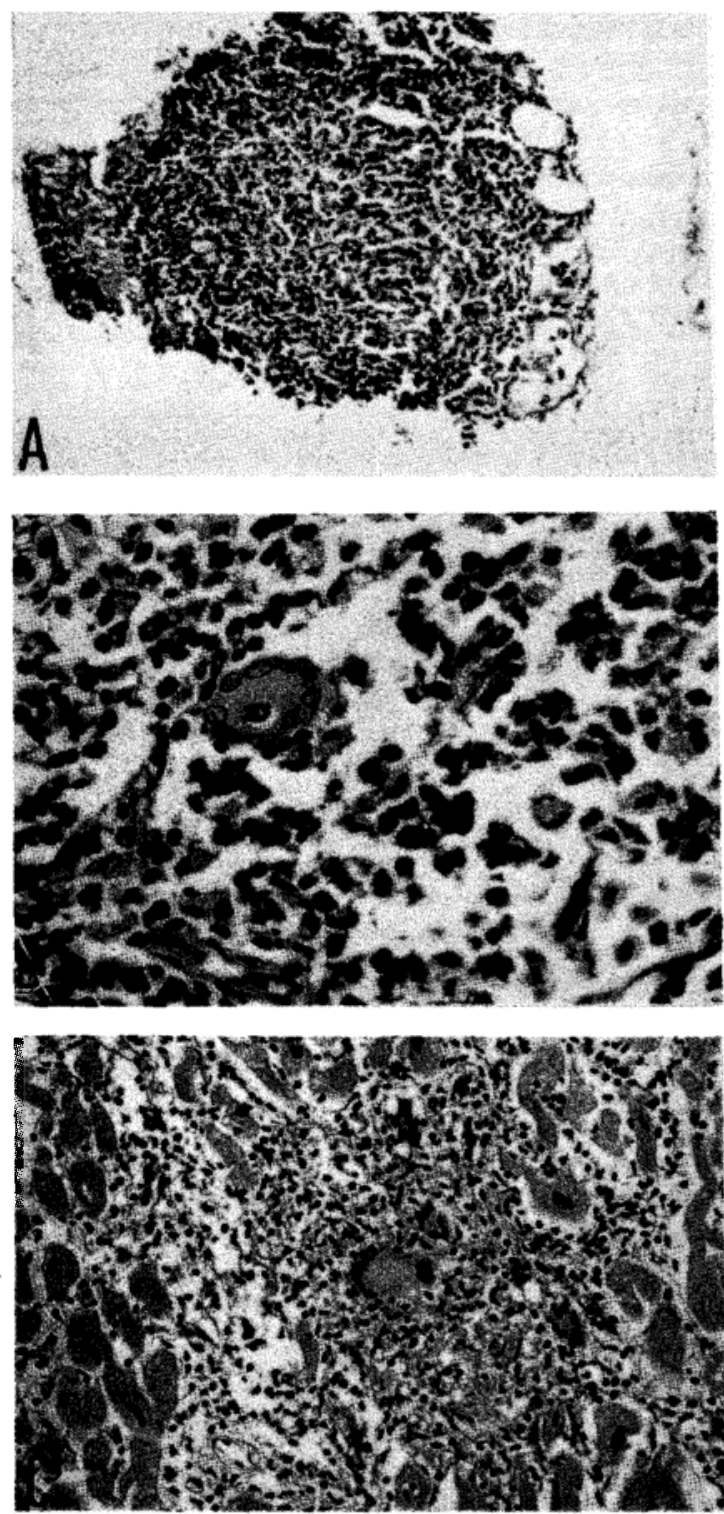

Fig. $10 A, B, C$ - Cão de raça não definida inoculado com a cepa Berenice-78 e autopsiado na fase crónica da infecção.Epicárdio (A) e Miocárdio (B e C). Inflamação crônica produtiva granulomatosa, com presenca de células gigantes, tipo Langhans (granulomas nas várias fases evolutivas). 
Lana M, Tafuri WL, Caliari MV, Bambirra EA, Chiari CA, Leite VHR, Barbosa AJA, Toledo MJO, Chiari E. Fase crônica fibrosante da tripanossomíase cruzi experimental no cão. Revista da Sociedade Brasileira de Medicina Tropical 21: 113-121, Jul-Set, 1988

neste animal em relação ao homem. Podemos dizer, segundo nossa experiência, que o cão poderá vir a ser o modelo ideal para o estudo dos mecanismos imunitários intimos, responsáveis pela mudança da fisionomia das reações locais e gerais, frente aos agentes agressores, quer sejam aqueles inerentes ao parasito, quer sejam aqueles inerentes ao hospedeiro. Ainda mais, a partir desses estudos, será possível compreender os mecanismos da fibrilopoese focal e difusa e sua modulação (neoformação e demoliçāo do colágeno). A fibrose talvez seja o fator patogenético mais importante para se compreender melhor a fisiopatologia da doença. A nosso ver forma-se colágeno para mais e esse fator é importantissimo no remanejamento de feixes de fibras musculares dos órgãos ocos e conseqüentemente alterações de sua fisionomia anatomofuncional ${ }^{23}$.

O modelo, por nós assim observado, parece preencher parcialmente os requisitos já mencionados
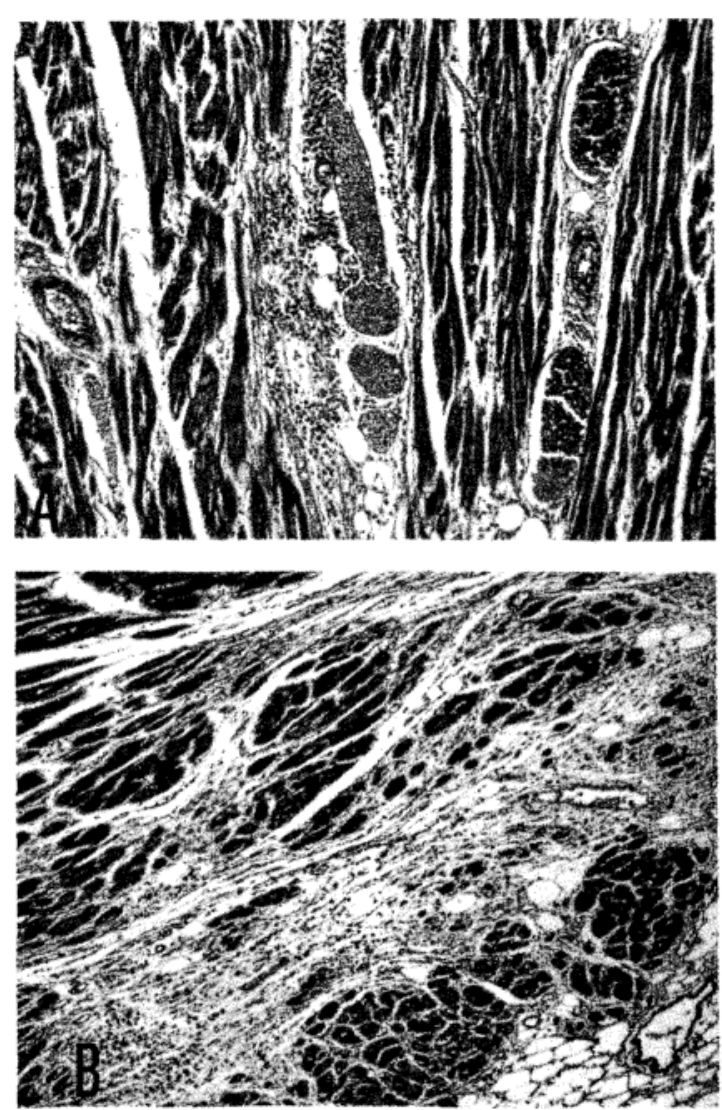

Fig. $11 A, B,-$ Cão Pinscher inoculado com o T. cruzi da cepa Colombiana e autopsiado sete anos após o inóculo. Miocardite crônica, com acentuado exsudato de células mononucleadas focal (A) ou difuso e acentuada (B) neoformação colágena entre células cardiacas, congestão e edema. de acordo com a $\mathrm{OMS}^{25}$, ou seja: o cão infectado que sobrevive à fase aguda da infecção pode conviver com o $T$. cruzi por mais de oito anos. Parasitos da cepa Colombiana, isolados desses cães com infecção crônica, foram capazes de infectar todos os camundongos albinos inoculados e apresentaram, para esses animais, menor virulência que tripomastigotas sangüineos dessa mesma cepa, antes de ser inoculada em cães e também em relação à população mantida através de passagens sucessivas em camundongos. Isso está de acordo com o já demonstrado, pois o tipo de manuseio do parasito pode influenciar em suas caracteristicas ${ }^{10} 1217$ 22. Possivelmente a permanência do T. cruzi, por mais de oito anos no cão, pode resultar em uma seleção de população, com conseqüente mudança de sua virulência. Tal fato já foi verificado com relação às cepas isoladas da paciente Berenice em duas ocasiões distintas ${ }^{17}$. Nesse caso também foi verificado que a cepa Berenice, isolada em 1978, apresentou características biológicas distintas da cepa isolada em 1962, e uma virulência muito menor para camundongos albinos e $\mathrm{C}_{3} \mathrm{H}$ isogênicos 16 . Essa cepa até agora mantida em laboratório através de passagens sanguineas sucessivas, em camundongos albinos, apresentou, antes de ser inoculada em cães, um comportamento muito semelhante ao já descrito em camundongos $\mathrm{C}_{3} \mathrm{H}$ isogênicos onde foi mantida anteriormente através de repiques sucessivos ${ }^{17}$.

A té o momento estamos com quatro cães crônicos, infectados com a cepa Colombiana, com xenodiagnóstico positivo e todos apresentando provas sorológicas reativas indicativas de persistência da infecção. Estes resultados são muito semelhantes ao observado, em pacientes humanos, na fase crônica da doença de Chagas 12 .

Dos 34 cães infectados com ambas as cepas (Colombiana ${ }^{13}$ e Be-7817), até o momento, seis apresentaram manifestações clínicas da doença crô nica. Todos os autopsiados revelaram nos exames anatomopatológicos: epicardite, miocardite crônica produtiva fibrosante, com presença às vezes de granulomas periganglionite, ganglionite, perineurite $\mathrm{e}$ neurite, com possível despopulação neuronal. Nos cães inoculados, com a cepa Colombiana, foram pesquisados anticorpos antineurônios na fase indeterminada, sendo a RIFI reativa ${ }^{7}$, bem como a pesquisa de parasita pela técnica de imunoperoxidade (PAP) ${ }^{8}$. Em nenhum dos cães, até o momento, foi detectada a forma digestiva.

\section{SUMMARY}

The authors found the fibrosing chronic chagasic cardiopathy with congestive heart failure in one out of the 21 dogs infected with the Colombian strain (five died in acute phase and four are allve) five out of the 13 animals infected with the Berenice-78 strain 
Lana M, Tafuri WL, Caliari MV, Bambirra EA, Chiari CA, Leite VHR, Barbosa AJA, Toledo MJO, Chiari E. Fase crônica fibrosante da tripanossomíase cruzi experimental no cão. Revista da Sociedade Brasileira de Medicina Tropical 21:113-121, Jul-Set, 1988

(eight died in acute phase) were observed until eight years of infection with $\mathrm{T}$. cruzi.

In view of these results, the author suggest that the dog could be a suitable experimental model for the study of the natural history of Chagas' disease. The dog conforms with the requisites of the World Health Organization (WHO) Steering Committee of Chagas' disease of the Programme for Research Training in Tropical Diseases.

Key-words: Trypanosoma cruzi. Chagasic cardipathy. Dog. Experimental model. Fibrosis.

\section{REFERÊNCIAS BIBLIOGRÁFICAS}

1. Andrade ZA. The camine model of Chagas' disease. Memórias do Instituto Oswaldo Cruz. Rio de Janeiro, Suppl. Vol. 79: 77-83, 1984.

2. Andrade ZA, Andrade SG. A patologia da doença de Chagas experimental no cão. Memórias do Instituto Oswaldo Cruz 75: 77-95, 1980.

3. Andrade ZA, Andrade SG, Sadigursky M. Damage and healing in the conducting tissue of the heart (an experimental study in dogs infected with Trypanosoma cruzi). The Journal of Pathology 143: 93-101, 1984.

4. Andrade ZA, Andrade SG, Sadigursky M, Maguire JH. Experimental Chagas'disease in dogs a pathologic and ECG study of the chronic indeterminate phase of the infection. The Archives of Pathology and Laboratory Medicine 105: 460-464, 1981.

5. Anselmi A, Gurdiel O, Suarez JA, Anselmi G. Disturbances in the $\mathrm{AV}$, conduction system in Chagas' myocarditis in the dog. Circulation Research 20: 56-64, 1967.

6. Anselmi A, Pifano FC, Suarez A, Domingues A, Vazquez AD, Anselmi G. Experimental Schizotrypanum cruzi myocarditis. Correlation between histopathologic and eletrocardiographic findings in experimental Chagas' heart disease. American Heart Journal 70: 638$656,1965$.

7. Bambirra EA. Infecção experimental em cães Pinscher pelo Trypanosoma cruzi (Chagas, 1909). Resposta imunitária do parasita, a antígenos exógenos e de tecidos do hospedeiro, no decurso da infecção. Tese de doutorado, Universidade Federal de Minas Gerais, Belo Horizonte, 1982.

8. Barbosa AJA. Método imunocitoquímico para a identificação de amastigotas do Trypanosoma cruzi em cortes histológicos de rotina. Revista do Instituto de Medicina Tropical de São Paulo 27: 293-297, 1985.

9. Brener $Z$. Therapeutic activity and criterion of cure on mice experimentally infected with Trypanosoma cruzi. Revista do Instituto de Medicina Tropical de São Paulo 4: 389-396, 1962.

10. Brener Z, Chiari E, Alvarenga NJ. Observations on Trypanosoma cruzi strains maintained over an 8-year period in experimentally inoculated mice. Revista do Instituto de Medicina Tropical de São Paulo 16: 39-46, 1974.

11. Cançado JR, Barra UD, Mourão OG, Alvares JM, Oliveira JPM, Salgado AA. Bases para a avaliação do tratamento especifico da doença de Chagas humana segundo a parasitemia. Revista da Sociedade Brasileira de Medicina Tropical 7: 155-166, 1973.

12. Carvalheiro JR, Collares EF. Estudos sobre o comportamento em camundongos de uma amostra altamente virulenta de Trypanosoma cruzi (amostra Y), após passagens em triatomineos, ratos e culturas. Revista Brasileira de Biologia 25: 169-175, 1965.

13. Federici EE, Abelmann WH, Neva FA. Chronic and progressive myocarditis and myositis in $\mathrm{C}_{3} \mathrm{H}$ mice

13. Federici EE, Abelmann WH, Neva FA. Chronic and progressive myocarditis and myositis in $\mathrm{C}_{3} \mathrm{H}$ mice infected with Trypanosoma cruzi. American Journal of Tropical Medicine and Hygiene 13: 272-280, 1964.

14. Goble FC. Observations on experimental Chagas' disease in dogs. American Journal of Tropical Medicine and Hygiene 1: 189-204. 1952.

15. Kramer Jr AW. Experimental Chagas' disease in purebred beagle dogs acutely infected with Trypanosoma cruzi (B strain). Revista do Instituto de Medicina Tropical de São Paulo 14: 291-300, 1972.

16. Lana M. Caracterização do Trypanosoma cruzi, cepas Berenice, isoladas da mesma paciente em diferentes periodos. Tese de Mestrado. Departamento de Parasitologia, Instituto de Ciências Biológicas, Universidade Federal de Minas Gerais p. 91, 1981.

17. Lana M, Chiari CA. Caracterização biológica comparativa das cepas Berenice e Berenice-78 de Trypanosoma cruzi isoladas da mesma paciente em diferentes periodos. Memórias do Instituto Oswaldo Cruz 81 : 247-253, 1986.

18. Laranja FS. Aspectos clínicos da moléstia de Chagas. Revista Brasileira de Medicina 10: 482-491, 1953.

19. Laranja FS, Andrade ZA. Chronic cardiac form of Chagas' disease in dogs. Arquivo Brasileiro de Cardiologia 35: 377-380, 1980.

20. Lopes ER, Tafuri WL, Chapadeiro E, Pires LL, Macedo V, Prata AR, Tanus R. Doença de Chagas em cães. Etudo anatomopatológico de animais naturalmente infectados. Revista do Instituto de Medicina Tropical de São Paulo 22: 135-143, 1980.

21. Marsden PD, Hagstrom JW. Experimental Trypanosoma cruzi infection in beagle puppies. The effect of variations in the dose and source of infecting trypanosomes and the route of inoculation on the course of the infection. Transactions of the Royal Society of Tropical Medicine and Hygiene 62: 16-824, 1968.

22. Phillips NR. Experimental studies on the quantitative transmission of Trypanosoma cruzi: aspects of the rearing maintenance and testing of vector material, and of the origin and course of infection in the vector. Annals Tropical Medicine and Parasitology 54: 397-414, 1960.

23. Tafuri WL. Patogenia da Doença de Chagas. Revista do Instituto de Medicina Tropical de São Paulo 29: 194-199, 1987.

24. Williams GD, Adams LG, Yaeger RG, McGrath RK, Bilderback WR. Naturally occurring trypanosomiasis (Chagas' disease) in dogs. Journal of the American Veterinary Medical Association, 171: 171-177, 1977.

25. World Health Organization. Report of the Scientific Working Group on the Development and evaluation of animal models for Chagas' Disease, Genève, pp. 23-24, 1984. 